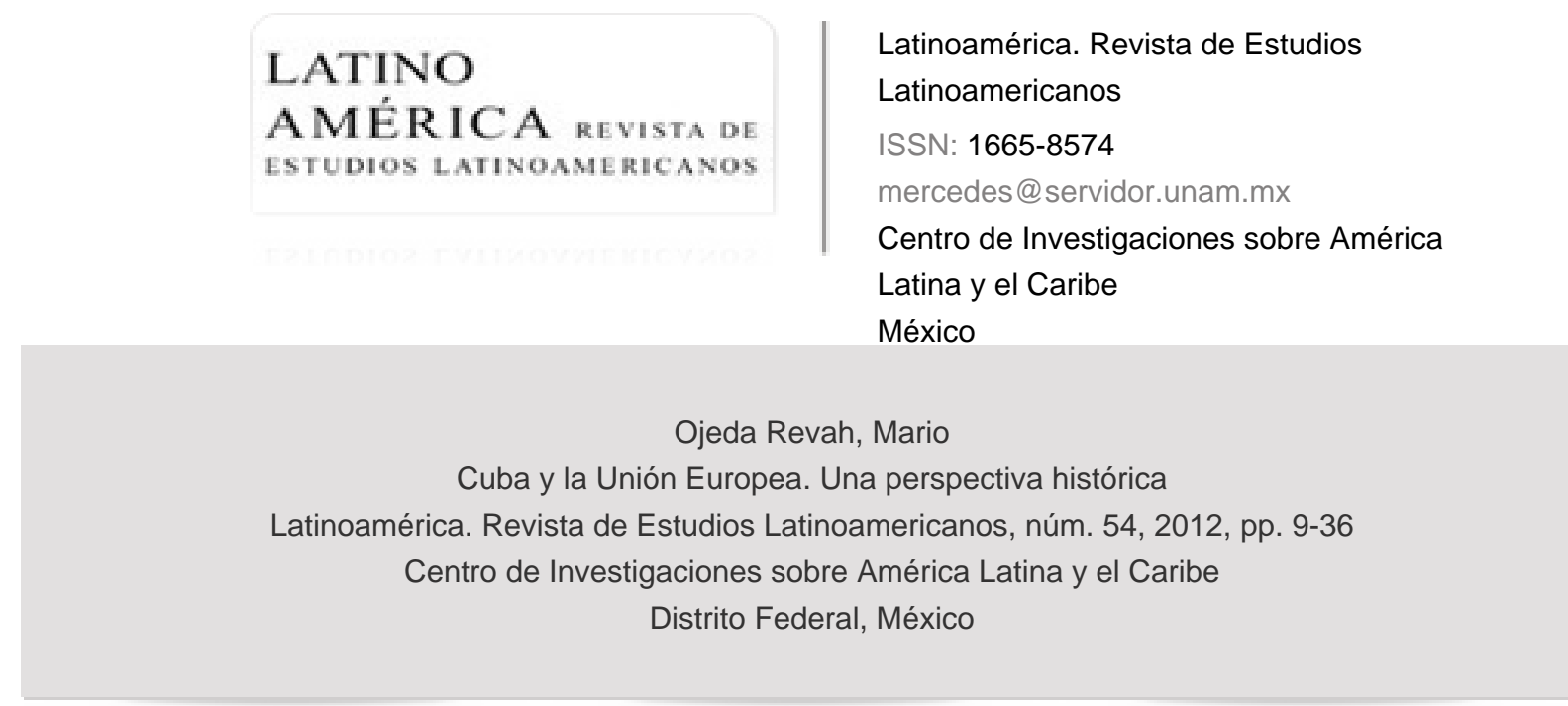

Disponible en: http://www.redalyc.org/articulo.oa?id=64023055002

- Cómo citar el artículo

- Número completo

- Más información del artículo

- Página de la revista en redalyc.org

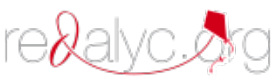

Sistema de Información Científica

Red de Revistas Científicas de América Latina, el Caribe, España y Portugal Proyecto académico sin fines de lucro, desarrollado bajo la iniciativa de acceso abierto 


\title{
Cuba y la Unión Europea. Una perspectiva histórica
}

\author{
Mario Ojeda Revab* \\ CIALC-UNAM
}

Resumen: El artículo pasa revista a las relaciones de Cuba con los principales países de Europa Occidental, desde el triunfo de la Revolución cubana hasta la caída del bloque soviético. Asimismo explora las relaciones del régimen revolucionario cubano con la Unión Europea durante el periodo especial, los constantes desencuentros entre la Isla y la UE, especialmente tras la asunción por el bloque europeo de la "Posición Común" y la represión de la disidencia durante la llamada "Primavera Negra". El artículo da cuenta del estancamiento actual de las relaciones bilaterales y de las perspectivas a corto y mediano plazo de las mismas.

Palabras Clave: Cuba, Unión Europea, Posición Común, Relaciones Internacionales.

ABSTRACT: The article reviews Cuba's relationships with the main countries of Western Europe after the triumph of the Cuban Revolution and up to the fall of the Soviet Block. It also explores the Cuban Revolutionary Regime's relationships with the European Union during the periodo especial, the constant disagreements between the Island and the EU (especially after the European Block's adoption of the "Common Position"), and the repression of dissent by the Castro regime during the so called "Black Spring". The paper recounts the current impasse in the bilateral relationship, and its prospects for the short and medium term.

Key words: Cuba, European Union, Common Position, International Relations.

* Centro de Investigaciones sobre América Latina y el Caribe de la unAm (morevah@unam.mx). 
esde el triunfo de la proclamación del carácter marxista de la Revolución cubana, por parte de Fidel Castro, en abril de 1961 y a lo largo de la Guerra Fría, Cuba y Europa Occidental formaron parte de bloques opuestos y antagónicos, en el marco de dicho conflicto. No obstante, los países más importantes de la región, Alemania, Italia, Francia y Reino Unido, mantuvieron inalteradas sus relaciones diplomáticas con el régimen instaurado por Fidel Castro y resistieron las presiones de Estados Unidos para apoyar el embargo impuesto por ese país contra la Isla en febrero de 1962.

Tan excepcional fue el desafío que Castro significó para Estados Unidos, que llevó al gobierno de John F. Kennedy a exigir a sus aliados de la otan que se implicaran en una región, la América Latina, que, hasta entonces, les había sido vedada según los términos de la Doctrina Monroe.

Pese a tales presiones, incluso la Gran Bretaña, el aliado más importante de Estados Unidos, cuyo gobierno conservador estuvo en manos de Harold Macmillan, hizo a un lado su "relación especial" con Washington y se negó a secundar al gobierno de ese país en sus intentos por aislar diplomáticamente primero y luego derrocar al gobierno revolucionario encabezado por Fidel Castro.

La mesurada actitud británica ante la Revolución cubana posee varias explicaciones. Por una parte estuvo fuertemente condicionada por su posesión continuada de varias colonias en el mar Caribe y por su propósito de llevar a cabo un proceso de descolonización controlado de las mismas. Es evidente que de haber tomado Londres una actitud más agresiva hacia Castro, éste hubiera podido haber causado graves complicaciones a tal designio. ${ }^{1}$

Hubo también motivaciones puramente económicas. Desde antes de la Revolución los intereses británicos tuvieron una importante presencia en la Isla. Baste recordar, a modo de ejemplo, que durante la dictadura de Fulgencio Batista, el Reino Unido fue uno de los más importantes proveedores de armamento en Cuba. En octubre de 1959 el gobierno norteamericano conminó al gobierno

Joseph S. Tulchin, Andrés Serbín, Rafael Hernández Rodríguez, Cuba and the Caribbean: regional issues and trends in the post-Cold War, Washington D. C., Woodrow Wilson International Center for Scholars, Latin American Program/Rowman \& Littlefield, 1997, p. 230. 
británico a cancelar la venta de aviones de combate Hawker a Cuba. Aunque Londres accedió a la demanda, el comercio con La Habana se mantuvo, y se constituyó en uno contencioso entre Washington y Londres, que alcanzó su mayor rispidez después de la venta de camiones Leyland a la Isla, lo que provocó un grave desencuentro entre las administraciones de Lyndon B. Johnson y Alec Douglas Home. ${ }^{2}$

Por último, para el Reino Unido el mantenimiento de vínculos diplomáticos y comerciales con Cuba, a contracorriente del embargo impuesto por Estados Unidos, fue no sólo un asunto meramente económico, sino también una cuestión de soberanía nacional. ${ }^{3}$ El tradicional rechazo británico al uso de sanciones comerciales fue apoyado tanto por tories como por laboristas, quienes vieron en las presiones norteamericanas una inadmisible injerencia en la política exterior y comercial del Reino Unido.

El pragmatismo británico fue evidente también en la negativa de Londres a asumir la representación de los intereses norteamericanos en la Isla, en caso de una hipotética ruptura de relaciones entre Washington y La Habana, posibilidad que Eisenhower sugirió al primer ministro británico y que éste rechazó sin miramientos. Cuando finalmente tuvo lugar dicha ruptura en enero de 1961, la Foreign Office británica consideró la decisión del gobierno norteamericano como el "resultado de un impulso emocional más que una consecuencia de una consideración racional", y optó por una política de "compromiso constructivo" con el gobierno revolucionario. ${ }^{4}$ El Reino Unido mantuvo sus vínculos comerciales con el régimen castrista, y la Isla se ha mantenido desde entonces como el sexto socio comercial británico en la América Latina.

Si bien los vínculos políticos cubano-británicos se han mantenido en un nivel medianamente constante desde 1959, la relación bilateral también ha te-

2 Sylvia Ellis, Historical dictionary of Anglo-American relations, Lanham, Maryland, Scarecrow Press, 2009, p. 89.

3 Loc. cit.

4 Daniel Rubiera Zim, "Straining the Special Relationship: British and U. S. Policies toward the Cuban Revolution, 1959-1961", en Cuban Studies, núm. 33, University of Pittsburgh Press, 2002, pp. 71-94. 
nido sus menguas. Fue el caso a partir de la llegada de Margaret Thatcher al poder en 1979, ya que el nuevo gobierno conservador favoreció un alineamiento más estrecho con Estados Unidos, lo cual se reflejó en una reducción notable de los intercambios comerciales bilaterales a partir de $1990 .^{5}$

No obstante, se continuaron las relaciones diplomáticas y políticas entre ambos países, incluso en periodos conflictivos, como la Guerra de las Malvinas, cuando Fidel Castro hizo a un lado sus diferencias con la dictadura militar de Galtieri y tomó partido por la Argentina, al denunciar la guerra como un "acto de agresión imperialista". ${ }^{6}$ Hubo incluso coincidencias entre ambos gobiernos: aunque por razones distintas, Londres y La Habana condenaron la invasión de Granada, emprendida por el gobierno de Ronald Reagan en 1983.

Las relaciones con las siguientes administraciones conservadoras de Margaret Thatcher y John Major se mantuvieron sin grandes estridencias. En 1997 el gobierno laborista de Tony Blair protestó vigorosamente contra la Ley HelmsBurton y objetó sus provisiones extraterritoriales, expresando su temor de que pudiera afectar los intereses empresariales británicos. No obstante, el Reino Unido condenó lo que consideró violaciones a los derechos humanos en Cuba y se pronunció a favor de un cambio democrático en la Isla. Con todo, las exportaciones británicas a Cuba sumaron 15 millones de libras en 1997 y sus importaciones provenientes de ese país sumaron un poco más. ${ }^{7}$ La Guerra del Golfo abrió una nueva brecha en las relaciones entre ambos países, que, con todo, no pasó nunca del plano declaratorio. Así mientras Tony Blair afirmó que le gustaría "ver una Cuba democrática", Castro atacó al premier británico, tachándolo de "lacayo del imperialismo yanqui". Pese a la retórica, las relaciones se mantuvieron inalteradas.

La tradición revolucionaria francesa y la voluntad de Charles de Gaulle de contrarrestar la hegemonía de Estados Unidos en el sistema internacional, fue-

5 Jorge I. Domínguez, To make a world safe for revolution: Cuba's Foreign Policy, Cambridge, Center for International Studies, Harvard University, 1989, p. 229.

6 Georges A. Fauriol, Eva Loser, Cuba: the international dimension, Nueva Jersey, Transaction Publishers Rutgers, 1990, pp. 52 y 53.

7 Ellis, op. cit., p. 126. 
ron, tal vez, los factores determinantes que llevaron a París a mantener inalteradas sus relaciones diplomáticas con La Habana, tras el triunfo de la Revolución castrista. El 8 de enero de 1959, mismo día en que Fidel Castro hizo su entrada a La Habana, de Gaulle tomaba posesión como primer presidente de la Quinta República francesa. Con todo, la relación no estuvo libre de problemas y hubo incluso frialdad y roces entre París y La Habana, en parte por el decidido apoyo de Cuba al flv en la Guerra de Independencia argelina. Francia dio su respaldo sin reservas a Estados Unidos, durante la Crisis de los Misiles, al enviar su fuerza naval estacionada en el Caribe, la cuarentena, impuesta por Washington contra la Isla. De todos los aliados europeos, Francia fue el país que prestó la ayuda más resuelta al gobierno de Kennedy. ${ }^{8}$

Este enfriamiento se vio reflejado también en un deterioro notable del comercio bilateral entre ambos países. Así, las exportaciones cubanas a Francia cayeron de $1.4 \%$ del valor total de las exportaciones cubanas en $1960 \mathrm{a}$ un ínfimo $0.3 \%$ en 1962; las importaciones provenientes de Francia cayeron de $2 \%$ a 0.2 del total en ese mismo periodo. ${ }^{9}$ No obstante, la inicial reticencia francesa a ir en contra de la política norteamericana que buscaba aislar al régimen de Castro fue efímera y durante la Guerra Fría continuó comerciando con Cuba, contribuyendo a consolidar al régimen revolucionario en una coyuntura crítica.

Después de la Independencia de Argelia y el fin de la Crisis de los Misiles, los obstáculos entre ambos países quedaron superados. Mientras De Gaulle buscaba reafirmar la independencia de Francia respecto de Estados Unidos, Cuba quería comercio en productos de alta calidad y más independencia de la URSS, especialmente tras el fiasco de la Crisis de los Misiles. En 1964 Cuba firmó un contrato con la firma francesa Berliot para la adquisición de 300 camiones pesados y tractores por valor de 10 millones de dólares. La transacción fue financiada por un crédito a 3 años, otorgado por el gobierno francés. Para 1967 Francia compraba 2.1 de las exportaciones cubanas y proveía $4.1 \%$ de sus importacio-

8 Maurice Vaisse, "La France et la crise de Cuba," en Histoire, économie et société, 13e année, núm. 1, 1994, La France et la Grande-Bretagne devant les crises internationales, p. 188.

9 Domínguez, op. cit., p. 187.

latino mérica 54

(MÉxICo 2012/1): 9-36 13 
nes. ${ }^{10}$ Eventualmente, Francia se convirtió en el principal socio comercial de Cuba en Europa Occidental, tan sólo detrás de España. ${ }^{11}$

Las relaciones entre ambos países se deterioraron nuevamente después de la presidencia de De Gaulle. En 1975, el gobierno de Valéry Giscard d'Estaing expulsó a tres diplomáticos cubanos, acusados de supuestos contactos con el terrorista Illich Ramírez, Carlos, que había asesinado a dos policías franceses, días antes. Pese a que Cuba negó cualquier vínculo con aquel, las relaciones se enfriaron considerablemente y la balanza comercial bilateral decayó muy por debajo de los promedios anuales de la década anterior. ${ }^{12}$

Uno de los vínculos diplomáticos más paradójicos del siglo xx fue, sin duda, la relación mantenida por los gobiernos de Francisco Franco y Fidel Castro entre 1959 y 1975, relación que ha intrigado a los historiadores, politólogos e internacionalistas, que han buscado explicar de diversos modos cómo dos regímenes tan disímiles, e incluso opuestos, ideológicamente pudieron, no obstante, mantener una relación no sólo intensa, sino incluso cordial.

Diversos autores han intentado dilucidar dicha contradicción por medio de diversas explicaciones, entre las que cabe destacar, la Hispanidad, es decir la existencia de vínculos culturales de tradición y ascendencia común, e incluso la "conexión gallega" entre ambos mandatarios.

Otras explicaciones, igualmente plausibles, tendrían que ver también con el factor emotivo: el "honor" de España había sido gravemente afectado por la Guerra Hispano-Americana de 1898 y esa "dignidad herida" había sido restaurada por la Revolución cubana. Desde una perspectiva pragmática y realista, se ha intentado explicar la relación bilateral a partir del empeño de las élites políticas del franquismo de dotar a España de una diplomacia independiente y propia, en tanto potencia media e influyente en la región, distanciándose de la lógica de la

${ }^{10}$ Ibid., p. 188.

${ }^{11}$ Cristina Johnston, France and the Americas: culture, politics, and bistory: a multidisciplinary encyclopedia, vol. 2, ABC-CLIO, 2005, p. 324.

12 Domínguez, op. cit., p. 196. 
Guerra Fría, al desempeñar un papel como intermediario entre el mundo occidental y la América Latina, especialmente entre Cuba y Estados Unidos. ${ }^{13}$

El triunfo de la Revolución cubana fue recibido por el régimen franquista con una mezcla de cautela y expectación. Con Cuba, al igual que con otros países latinoamericanos, a menudo inestables, en virtud de sus frecuentes golpes de Estado, España manejó una política de no intervención e hizo uso de la Doctrina Estrada (los gobiernos o los cambios de gobierno no deben ser juzgados por otras naciones) ${ }^{14}$

Cuba y España negociaron un ambicioso acuerdo comercial en 1960, "el más amplio acuerdo comercial bilateral firmado jamás por España con cualquier país extranjero," mismo que fue renovado en 1963 y 1966. La compañía Iberia fue durante largos años la única línea aérea occidental en operar vuelos a la Isla, aunque debió suspenderlos temporalmente, durante y poco después de las Crisis de los Misiles.

De modo sorpresivo, el anticomunista dictador español rompió el bloqueo estadounidense a la Isla. Franco consideraba que el pueblo cubano era lo primordial y que Cuba había caído en las garras del expansionismo marxista de la Unión Soviética, empujada por los abusos coloniales de Estados Unidos. Franco incluso sugirió a los cubanos no gastar "ni un céntimo, ni un solo céntimo" en indemnizar por las expropiaciones revolucionarias a los norteamericanos. ${ }^{15} \mathrm{Cas}-$ tro, en su momento, agradeció la continuidad del comercio español, y el apoyo del gobierno franquista en su calidad de puente hacia el exterior y de foro de diálogo internacional en épocas de ostracismo impuesto.

Con todo, la relación no estuvo exenta de fricciones, tal y como queda de manifiesto con la expulsión del embajador de Franco ante La Habana, Juan Pablo de Lojendio, en enero de 1960, al presentarse intempestivamente en los estudios de la televisión cubana, donde Castro había acusado a la Embajada española

13 Haruko Hosoda, "The Franco regime's contradiction: Its foreign policy toward Cuba", en Waseda Global Forum, núm. 5, 2008, p. 17.

${ }^{14}$ Ibid., p. 22.

15 Manuel de Paz Sánchez, Franco y Cuba. Estudios sobre España y la Revolución, Santa Cruz de Tenerife, IDEA, 2006, pp. 301 y 302. 
de conspirar contra la Revolución cubana. El diplomático interrumpió la transmisión, exigió una disculpa pública y, acto seguido, fue conminado allí mismo a abandonar la Isla en un plazo perentorio. Lojendio fue declarado persona non grata y las relaciones se rebajaron en un nivel de encargado de negocios, pero España se abstuvo de participar en el embargo decretado por Estados Unidos contra Cuba. ${ }^{16}$ En cuanto a Lojendio, lejos de ser felicitado por Franco, fue censurado y marginado en el servicio exterior español. Las relaciones plenas entre ambos países se restablecieron en 1973. En 1975, a la muerte de Franco, Castro decretó tres días de luto oficial, ${ }^{17}$ gesto que no tuvo un año después con el dirigente chino Mao Zedong. ${ }^{18}$

Con la llegada de la democracia a España se intensificaron los contactos políticos y la relación económica. Fue precisamente Adolfo Suárez el primer estadista occidental en visitar oficialmente La Habana, en septiembre de 1978. Castro

${ }^{16}$ Manuel de Paz Sánchez, Zona rebelde: la diplomacia española ante la Revolución cubana (1957-1960), Centro de la Cultura Popular Canaria, 1997, pp. 308-310; Hosoda, op. cit., pp. $15-$ 24.

${ }^{17}$ Anne Geyer, Guerrila Prince. The Untold Story of Fidel Castro, Kansas City, Little Brown and Co., 1991, p. 35; John Lukacs, The End of the Twentieth Century and the end of the Modern Age, Boston, Massachusetts, Ticknor \& Fields, 1993, p. 35; Domínguez, op. cit., p. 5. Existe una fuente de primera mano que acredita el hecho. El entonces corresponsal de la agencia EFE en La Habana, Francisco Rubiales, envió un despacho publicado al día siguiente en diversos medios internacionales como Excélsior de México, Le Monde de Francia y el International Herald Tribune: Luto oficial y enorme impacto en el gobierno y la opinión cubanos, La Habana, 24 de noviembre, 1975. "Pocas horas después de conocerse la muerte del general Franco, el Gobierno revolucionario de Cuba decretó luto oficial por tres días. Desde el jueves las banderas ondean a media asta en todo el territorio cubano. El Presidente de la República, doctor Osvaldo Dorticós, ha enviado un mensaje de condolencia al presidente del Gobierno español, Carlos Arias Navarro. Aquí, en la capital cubana, el ministro de Relaciones Exteriores de Cuba, Raúl Roa, se sumó el viernes a las miles de personas que firmaron en los libros de condolencia abiertos en la Cancillería española. Después de firmar se entrevistó con el embajador de España en Cuba, don Enrique Suárez de Puga".

Con posterioridad, Rubiales ha narrado cómo fue entonces objeto de presiones por parte de autoridades cubanas, por haber hecho pública tal información y cómo tales amagos estuvieron a punto de derivar en su expulsión de la Isla, medida que fue impedida in extremis por el propio Fidel Castro. Véase su propio testimonio. En http://blogs.periodistadigital.com /votoenblanco.php/2007/10/03/cuba_el_dia_que_murio_franco.

${ }^{18}$ Paz Sánchez, op. cit., p. 375. 
tuvo varios gestos políticos hacia Suárez, entre los que se incluyó la puesta en libertad de un preso político español, permisos de salida de Cuba para españoles con doble nacionalidad y la solución de las indemnizaciones pendientes. La visita significó un espaldarazo políico mutuo. Mientras Castro salía del aislamiento del Tercer Mundo, el presidente español ganaba legitimidad interna frente a la oposición socialista, que lo acusaba de ser un reaccionario. ${ }^{19}$

Al llegar los socialistas al poder en España, en octubre de 1982, las relaciones de toda índole entre ambos países se intensificaron aún más. En febrero de 1984, Castro se presentó de modo inesperado en el aeropuerto de Barajas, junto con el dirigente sandinista Daniel Ortega, en una escala técnica, tras un viaje oficial a Moscú, con motivo de los funerales de Yuri Andropov. Después de una improvisada conferencia de prensa en la que el comandante cubano se congratuló de pisar tierra española por vez primera, el presidente español Felipe González ofreció un banquete en el Palacio de la Moncloa a ambos mandatarios. ${ }^{20}$ Las inversiones españolas en la Isla se incrementaron espectacularmente en el periodo, fueron especialmente importantes en los rubros de turismo, telecomunicaciones y alimentación, con una inversión directa total acumulada en Cuba equivalente a 100 millones de dólares, a comienzos de 1996.

Pese a la buena relación, existieron diferencias entre Madrid y La Habana, como la liberación pendiente de Eloy Gutiérrez Menoyo, líder histórico de la Revolución, quien llevaba 21 años preso en la Isla y tenía la nacionalidad española. Al final, tras intensas negociaciones entre las cancillerías de ambos países, Castro accedió a liberarlo, un mes después de la visita oficial de Felipe González a Cuba, en noviembre de $1986 .{ }^{21}$

Encuentro que se había pospuesto ya que un año antes había tenido lugar la crisis desatada por el viceministro de Planificación, Manuel Sánchez Pérez, al solicitar asilo político en España. Cuatro funcionarios armados de la Embajada cubana intentaron secuestrarlo cerca de la madrileña Plaza de Colón, pero agen-

${ }^{19}$ El País, Madrid, 10-12 de septiembre, 1978.

20 "La visita de Fidel Castro", en El País, Madrid, 18 de febrero, 1984.

${ }^{21}$ Joaquín Roy, España y Cuba: 1898-1998. La siempre fiel. Un siglo de relaciones hispano-cubanas, 1898-1998. Del desastre a Helms-Burton, Madrid, Los Libros de la Catarata, 1999, p. 82 
tes del CESID español lo impidieron. Los funcionarios cubanos fueron expulsados del país. ${ }^{22}$

Otros diferendos entre ambos países tuvieron que ver con la presencia de etarras en la Isla en los años ochenta, las duras declaraciones de Castro acerca del Quinto Centenario y la crisis de los cubanos refugiados en la Embajada española en julio de 1990, pero en ningún caso enfriaron la relación. ${ }^{23}$

En noviembre de 1986 tuvo lugar la mencionada visita de Felipe González a Cuba. En aquella época, el encuentro fue considerado el más importante suceso de la gira iberoamericana que llevó a cabo González y que incluyó a Ecuador y Perú. En Cuba, el ex presidente socialista recibió la máxima condecoración cubana, la orden "José Martí" y afirmó que la recibía con gran satisfacción en nombre de todo el pueblo español.

La visita fue un acontecimiento político de trascendencia, dado que se trataba del primer jefe de gobierno de un país miembro de la entonces ceE y de la OTAN que realizaba una visita oficial a Cuba. Antes que González, Adolfo Suárez había visitado la Isla como presidente de España, pero entonces el país aún no formaba parte de la CEE y la OTAN. La visita de González puso fin a varios contenciosos entre ambas naciones, como el tema de las indemnizaciones pendientes a ciudadanos españoles expropiados en sus bienes por la Revolución, o la situación de Eloy Gutiérrez Menoyo, lo que reflejó el buen entendimiento entre ambos gobernantes. ${ }^{24}$

Tras muchos aplazamientos, Castro finalmente efectuó una visita oficial a España, en julio de 1992, con motivo de la II Cumbre Iberoamericana de jefes de Estado y de gobierno. Durante su visita Castro viajó a Sevilla, departió con el presidente autonómico gallego Manuel Fraga, y visitó Láncara, la aldea natal de su padre. González aprovechó la presencia del líder cubano en España para pedirle que convocara a elecciones y que liberara a presos políticos. ${ }^{25}$

22 "Havana Defector Knows Arms Data", en New York Times, 17 de diciembre, 1985.

${ }^{23}$ Joaquín Roy, "España y Cuba: iuna relación muy especial?", en Afers Internacionals, núm. 31, Centro de Estudios y Documentación Internacionales de Barcelona, pp. 147-166.

${ }^{24}$ El País, Madrid, 16 de noviembre, 1986.

${ }^{25}$ El Pais, Madrid, 23-29 de julio, 1992 
Sin duda, las relaciones entre La Habana y Madrid durante el gobierno de José María Aznar fueron las más tensas en la historia reciente de ambos países. Entre la guerra de declaraciones, expulsiones de políticos y diplomáticos, incluida la negación del plácet al embajador español, José Cordech, en la Isla, desde 1996 hasta 2003, La Habana y Madrid vivieron sus momentos más críticos hasta la llegada de Zapatero, cuando comenzó la distensión.

Destacan de esa etapa, las duras declaraciones de Fidel Castro contra Aznar, a quien calificó de "personaje de estirpe e ideología fascista" ${ }^{\text {"26 }}$ y la campaña de línea dura que desarrolló en 1996 el gobierno de Aznar para forzar el cambio político en Cuba; cruzada que culminó en la adopción por la Unión Europea (UE) de la llamada Posición Común hacia Cuba en 1996. Aznar no sólo se opuso a que se programara un viaje oficial de los Reyes a Cuba en 1998, coincidiendo con el centenario de la Guerra Hispano-Americana, sino que se asoció abiertamente con los sectores más recalcitrantes del exilio cubano, como testimonia su cercanía con Jorge Mas Canosa. ${ }^{27}$

Un caso especial fue el de la República Federal Alemana, nación que pese a encontrarse como Cuba en la primera línea de fuego de la Guerra Fría, mantuvo inalterados sus vínculos diplomáticos con el gobierno de Fidel Castro, incluso después de que éste declarase su adhesión al comunismo. Las relaciones de la RFA con el gobierno revolucionario cubano estuvieron fuertemente condicionadas por las presiones surgidas de la tensión en las relaciones Este-Oeste, más que por un diferendo intrínseco entre ambas naciones.

El 13 de enero de 1963, Alemania Federal rompió relaciones con Cuba, en virtud de la Doctrina Hallstein, ${ }^{28}$ debido a que la Isla y la República Oriental de Alemania decidieron elevar al rango de embajadas sus respectivas misiones. Ello no obstó para que las filiales españolas de varias corporaciones alemanas siguieran comerciando y realizando inversiones con Cuba. Las relaciones diplo-

${ }^{26}$ El País, Madrid, 27 de julio, 2003.

${ }^{27}$ ABC, Madrid, 29 de enero, 1996.

${ }^{28}$ Sostenía que la RFA era la única representante del pueblo alemán y, por consiguiente, nunca establecería relaciones diplomáticas con ningún país que reconociera diplomáticamente a la RDA, a excepción de la uRSs. El fin último de la Doctrina Hallstein era el aislamiento internacional de la RDA. 
máticas entre ambos países sólo fueron reanudadas en 1975 bajo el gobierno socialdemócrata de Helmut Schmidt. ${ }^{29}$

Al desaparecer la RDA Cuba perdió un mercado equivalente a 5\% del comercio exterior cubano. ${ }^{30}$ La anexión de la RDA por la RFA en 1990 tuvo un enorme impacto para la economía cubana al interrumpirse las relaciones con quien había sido su segundo socio económico, producto de la imposición por la RFA de condicionamientos políticos para su continuación.

Así en septiembre de 1990, el entonces ministro de Cooperación de la RFA, Jürgen Wanke, declaró cancelada la cooperación oficial de su país al desarrollo en Cuba, condicionándola a su democratización. De la cooperación con la RDA sólo sobrevivieron programas muy puntuales en el ámbito académico. ${ }^{31}$ Ningún país en América Latina resintió tanto la reunificación alemana como Cuba.

No obstante, para mediados de los noventa, dicho enfriamiento comenzó a revertirse, al aumentar notablemente el intercambio comercial entre ambos países y al convertirse Alemania en uno de los principales emisores de turismo a Cuba. ${ }^{32}$ Con la llegada al poder, en noviembre de 2005, del gobierno conservador encabezado por Angela Merkel, las relaciones germano-cubanas han entrado en una nueva fase de distanciamiento.

Tras el desplome del bloque socialista y la unss, y el consiguiente fin de la cooperación económica y comercial con el Consejo de Ayuda Mutua Económica (CAME) en 1991, Cuba perdió casi 70\% de los mercados socialistas, y para hacer más crítica aún su situación, el bloqueo se profundizó. Cuba entró en el denominado periodo especial y la prioridad diplomática cubana en los años noventa pasó a ser la reintegración en la América Latina y el Caribe y el establecimiento

29 Leticia Bobadilla González, México y la OEA: los debates diplomáticos, 1959-1964, México, Secretaría de Relaciones Exteriores-Dirección General del Acervo Histórico Diplomático, 2006, p. 190; Jorge I. Domínguez, To make a world safe for revolution: Cuba's foreign policy, Harvard University Press, 1989, pp. 200 y 201.

${ }^{30}$ Francisco Florentino, "Factores de confluencia y divergencia Cuba-Alemania a la sombra de las leyes Torricelli y Helms Burton. Un estudio de caso", ponencia en LASA 98, XXI International Congress, p. 3.

${ }^{31}$ Ibid., pp. 4 y 5.

32 Ibid., pp. 8 y 11 
de una nueva relación política y económica con Europa Occidental, en el contexto del vigente embargo norteamericano. ${ }^{33}$

Ante la necesidad urgente de ayuda externa, el gobierno cubano llevó a cabo amplias reformas para facilitar la inversión extranjera en la Isla. Varios miembros de la uE aprovecharon la oportunidad para invertir en el único territorio en el mundo libre de la competencia de compañías estadounidenses y en pocos años la ue se convirtió en el socio inversionista y comercial más importante de Cuba. A pesar de los reveses ocasionados por trances tales como la Ley Helms-Burton, firmada por el presidente Clinton en marzo de 1996, dicha estrategia probó ser relativamente exitosa. Para mediados de los noventa, 30\% del comercio exterior de Cuba se llevaba a cabo con cada una de esas regiones, comparado con 8\% con Europa y 5\% con América Latina y el Caribe en los años ochenta. ${ }^{34}$

En octubre de 1992, el Congreso norteamericano, convencido de que el gobierno cubano habría de caer también y presionado por el influyente lobby cubano-americano asentado en Miami, aprobó la llamada Cuban Democracy Act (también conocida como Ley Torricelli). Según su autor, la ley fue planteada para "causar estragos a esa isla", al endurecer e internacionalizar el embargo, y castigar a individuos y empresas extranjeras, señaladamente europeas, que invertían y hacían negocios en Cuba.

En 1996, el Congreso norteamericano aprobó una segunda ley para desalentar e intimidar a los inversionistas extranjeros que hacían negocios en Cuba, la Cuban Liberty and Democratic Solidarity Act (también conocida como la Ley

${ }^{33}$ Véase Marjorie Lister, The European Union and the South: relations with developing countries, Londres, Routledge, 1997, p. 166 y Miguel García Reyes, Cuba después de la era soviética, México, El Colegio de México, 1994, pp. 217-223.

${ }^{34}$ Hoy, nuevamente, los términos del comercio exterior cubano han cambiado. A medida que la relación con Europa se ha deteriorado y los vínculos con Venezuela y China se han estrechado, el comercio con Europa ha pasado a un marginal tercer puesto: China 23\%, Canadá 19.5\%, Venezuela 10.4\%, España 6.5\%, Países Bajos 4.4\% (2009). Venezuela y China siguen siendo los principales socios comerciales de Cuba, mientras que Canadá desplazó en 2007 a España de la tercera posición, según información oficial divulgada en las páginas de Internet de la Oficina Nacional de Estadísticas (ONE). En http://www.one.cu/aec2009/esp/08_tabla_cuadro.htm. Véase también, "Cuba: cinco principales socios comerciales (exportación e importación de bienes), 2006 (en millones de pesos)" en Anuario estadístico de Cuba 2006, La Habana, one, 2007. 
Helms-Burton), que buscaba entre otras cosas: castigar a las empresas extranjeras con operaciones en Cuba mediante la denegación de visas a sus empleados, ejecutivos y sus familias; permitir reclamaciones legales en cortes estadounidenses por tierras y propiedades nacionalizadas por el gobierno revolucionario de Cuba; prohibir a las corporaciones y ciudadanos estadounidenses ofrecer financiamiento a cualquier persona de un tercer país que utilizara propiedades en Cuba, que hubieran pertenecido en el pasado a empresas norteamericanas. Aunque Estados Unidos carecía de jurisdicción para poner en vigor tales disposiciones y que ambas leyes son claramente extraterritoriales en espíritu y notoriamente contrarias al Derecho Internacional, intentó aplicarlas.

La Ley Helms-Burton fue condenada enérgicamente por el Consejo de Europa, la Unión Europea, Gran Bretaña, Canadá, México y otros aliados de Estados Unidos que mantenían relaciones comerciales normales con Cuba. Los gobiernos de esos países argumentaron que la legislación iba en contra del espíritu del Derecho Internacional y la soberanía de terceros países. ${ }^{35}$

Tras una denuncia presentada por la Unión Europea en la Organización Mundial del Comercio (OMC) se formó un panel de solución de controversias. Posteriormente, el trabajo del panel fue suspendido para encontrar una solución a través de negociaciones. Después de un año, el grupo perdió su jurisdicción sobre el asunto, y la ue decidió no seguir discutiendo sobre el tema ante la omc. La Unión Europea presentó entonces un Reglamento del Consejo (núm. 2271/96) (Ley vinculante para todos los estados miembros) en el que se declaraban a las disposiciones extraterritoriales de la Ley Helms-Burton como inexigibles en la uE, permitiendo la recuperación de los daños y perjuicios impuesta en virtud del mismo. ${ }^{36}$

Hasta 1993 las relaciones de Cuba con los países miembros de la ue se dieron en un plano bilateral, por medio de las misiones de cada país, sitas en La Habana y a través de sus contrapartes cubanas en las capitales europeas. La

35 El País, Madrid, 27 de junio, 1996.

${ }^{36}$ Véase "вu Counters Helms-Burton Act", en Reuters, 28 de octubre, 1996 y "Three Allies Join Call Against Cuba Embargo; Eu Unites to Protest Helms-Burton Law", en Washington Post, 3 de noviembre, 1996. 
Comisión Europea inició sus actividades en Cuba en 1993, cuando su Departamento de Ayuda Humanitaria, la European Commission Humanitarian Aid and Civil Protection (ECHO), facilitó ayuda de emergencia a la población afectada por el meteoro conocido como "tormenta del siglo". ${ }^{37}$ Desde entonces dichos vínculos se han caracterizado por vaivenes frecuentes, oscilando entre efímeras coincidencias y constantes desencuentros.

Desde su origen el Mercado Común o Comunidad Económica Europea careció de una política común de cara al exterior. No fue sino hasta febrero de 1992 que el principio y la voluntad de llevar a cabo una Política Exterior y de Seguridad Común (PESC) fueron finalmente formalizados, mediante el Tratado de Maastricht. Según lo estipulado en el Tratado de la Unión Europea, en su artículo 17 y siguientes, un alto representante, encargado de conducir dicha política exterior, debía ser nombrado por el Consejo Europeo por mayoría cualificada con la aprobación del presidente de la Comisión. En octubre de 1999 Javier Solana fue nombrado para desempeñar dicha función, cargo coloquialmente conocido como "Mr. PESC", y que dirigió durante una década. No obstante, sus funciones se vieron grandemente acotadas ante la falta de acuerdo entre los países miembros de la Unión, los cuales continuaron dando prioridad a sus políticas exteriores nacionales.

Aunque los países de la ue fueron conscientes sobre la necesidad de coordinar sus actuaciones en materia de defensa y política exterior, no ha sido éste un objetivo fácil de alcanzar. En 2009, al entrar en vigor el Tratado de Lisboa, el cargo fue elevado de categoría y dotado, al menos en principio, de mayores poderes. El alto representante de la Unión para Asuntos Exteriores y Políitica de Seguridad (AR), o también ministro de Asuntos Exteriores de la Unión (según la terminología de la malograda Constitución europea) estaría encargado de dirigir y ejecutar toda la política exterior de la Unión Europea. Con dicho impulso se buscaba dar lugar a una mayor coherencia, influencia y visibilidad a la Unión en la escena internacional y en más peso en sus relaciones con otros países y organismos institucionales.

${ }^{37}$ En http://ec.europa.eu/echo/files/policies/evaluation/2000/cuba1.pdf. 
En noviembre de 2009, Fredrik Reinfeldt, presidente rotatorio de la UE, anunció ante los medios que, por acuerdo entre los jefes de Estado y de gobierno reunidos en Bruselas en Consejo Europeo extraordinario, Catherine Ashton había sido designada como alta representante de la Unión para Asuntos Exteriores y Política de Seguridad, el cargo de Javier Solana, refundado completamente por el Tratado de Lisboa de diciembre de 2007 y que recogía las competencias del ministro de Asuntos Exteriores de la Unión contemplado en la nonata Constitución Europea. ${ }^{38}$

El alto representante es el jefe de la diplomacia comunitaria, coordina la acción exterior de la Unión en el seno de la Comisión Europea como uno de sus vicepresidentes y es el encargado de las relaciones internacionales y, como mandatario del Consejo, dirige y ejecuta la política exterior y de seguridad común de la Unión (incluyendo la política común de seguridad y defensa), es jefe y dirige el Servicio Europeo de Acción Exterior, en proceso de construcción.

En diciembre de 1996, la Unión Europea, que sustituyó a la Comunidad en 1993, asumió una Posición Común sobre Cuba por medio de la Resolución 96697-CFSP basada en una iniciativa presentada por el gobierno de José María Aznar; dicha disposición supuso el primer documento de política exterior vinculante para todos los países miembros con un país latinoamericano. ${ }^{39}$

El documento señala que "la Unión Europea considera que una plena cooperación con Cuba dependerá de las mejoras en el respeto de los derechos humanos y las libertades fundamentales". Asimismo, establece que "el objetivo de la Unión Europea en sus relaciones con Cuba es favorecer un proceso de transición hacia una democracia pluralista y el respeto de los derechos humanos y libertades fundamentales, así como una recuperación y mejora sostenibles del nivel de vida del pueblo cubano". Según dicha disposición es más probable que una transición hacia la democracia ocurra en Cuba de forma no violenta, si el ré-

${ }^{38}$ The Guardian, Londres, 20 de noviembre, 2009.

39 96/9677PESC Posición Común, de 2 de diciembre de 1996, definida por el Consejo en virtud del artículo J.2 del Tratado de la Unión Europea, sobre Cuba en Diario Oficial de la Unión Europea, núm. L322 de 12/1271996. Véase también, "Los Quince aprueban la propuesta española para condicionar las relaciones con Cuba", en El País, Madrid, 3 de diciembre, 1996. 
gimen la permite o la inicia. ${ }^{40}$ Por otra parte su tesis apunta a que la transición interna debe sostenerse en la integración de Cuba a la comunidad internacional.

Los ministros europeos reafirmaron su política de "presión sin acoso" para lograr la democratización del régimen de Fidel Castro, una estrategia claramente diferenciada de la de Washington. Sin embargo, acentuaron la reclamación de los derechos humanos y el fin de las persecuciones políticas en la Isla, al tiempo que mostraron su disposición a apoyar financieramente cada uno de los pasos de apertura que eventualmente diese La Habana. Los más críticos hacia la propuesta inicial española, como Bélgica, Suecia y Francia, terminaron por aceptarla al atenuar su dureza inicial. Como cabía esperar, Cuba reaccionó airadamente a la puesta en vigor de la Posición Común, calificándola de intromisión inaceptable en los asuntos internos del país.

Ciertamente, la Posición Común fue redactada en términos de una condicionalidad a priori, es decir, como un prerrequisito a la negociación misma, subordinándola a cambios políticos y económicos, lo que, sin duda, constituye un trato diferenciado y, por lo tanto discriminatorio respecto a terceros países. En efecto, la mayoría de los gobiernos de los estados signatarios de dicho acuerdo no destacan precisamente por su respeto a los derechos humanos más elementales, lo cual no ha sido óbice para su integración al mismo. De hecho, si la cláusula de elementos esenciales del Acuerdo fuera aplicada en sentido estricto, más de la mitad de los países signatarios deberían ser sancionados o expulsados sin más de la asociación. El hecho de que la uE no haya impuesto condiciones semejantes a otros socios, imponiéndoles consideraciones relativas a la democracia y los derechos humanos, permite hablar de un doble rasero aplicado por la ue en sus relaciones con Cuba en particular. ${ }^{41}$

La Posición Común de la Unión Europea respecto a Cuba, ratificada en sucesivas cumbres, ha hecho de la democratización de la Isla (es decir del cambio de régimen) y del respeto a los derechos humanos la condición sine qua non

\footnotetext{
${ }^{40} \mathrm{Ibid}$.

${ }^{41}$ Evelio Díaz Lezcano, "Las relaciones Unión Europea-Cuba. Evolución y perspectivas", en Clío América, vol. 1, núm. 2, noviembre de 2007, pp. 260 y 261.
} 
para el establecimiento de vínculos más estrechos y para la concesión de trato de nación más favorecida, semejante al acordado por el bloque supranacional al grupo de países en vías de desarrollo en África, el Caribe y el Pacífico (ACP). Cabe recordar que en dos ocasiones la postura mantenida por la uE ha obligado a Cuba a retirar su candidatura de adhesión al acuerdo de Cotonou que reemplazó en el año 2000 a la Convención de Lomé. ${ }^{42}$

En 1998, el Parlamento europeo puso en marcha un mecanismo de reconocimiento y homenaje a todas aquellas personas u organizaciones que trabajan en defensa de los derechos humanos, y muy particularmente por la libertad de expresión, dentro y fuera de las fronteras de la uE: el Premio Sájarov a la libertad de conciencia. Dicho galardón ha reconocido en tres ocasiones la lucha de la disidencia cubana por los derechos y libertades fundamentales en la Isla. En 2010 el activista cubano Guillermo Fariñas se convirtió, después de Oswaldo Payá (2002) y las Damas de Blanco (2005), en el tercer Sájarov que se otorgó a la disidencia cubana, tensando aún más las relaciones entre Cuba y el bloque europeo.

La ue es el más importante socio comercial de Cuba, uno de sus principales inversionistas, un notable proveedor de turistas de la Isla y su principal socio en cooperación para el desarrollo. ${ }^{43}$ Pese a ello, Cuba sigue siendo el único país de América Latina y el Caribe que no ha firmado un acuerdo de cooperación con la Unión Europea, después de varios intentos fallidos. El 10 de marzo de 2000 Cuba solicitó por primera vez, sin éxito, su ingreso al Convenio de Cotonou, que regula las relaciones económicas y de cooperación entre la Unión Eu-

${ }^{42}$ La noción de estados ACP se remonta al "Grupo de Estados ACP, formalmente constituido en 1975 a través del Acuerdo de Georgetown, inicialmente suscrito por 46 estados africanos, caribeños y del Pacífico. En la actualidad, el grupo AcP engloba 79 naciones, 78 de las cuales son signatarias del Acuerdo de Cotonou (Cuba es la excepción).

${ }^{43}$ Para 2003 los países miembro de la ue proveían poco más de la mitad de los turistas en Cuba, más de la mitad de las 400 empresas conjuntas de inversión extranjera en la Isla, mientras que la ue era el más importante donante de ayuda. En 2001 y 2002 la ue fue el socio comercial más importante de Cuba. Las exportaciones de la uE a Cuba equivalieron a 1430 millones de euros (el mayor porcentaje 44\% procede de España, le siguen Italia y Francia), mientras que las importaciones provenientes de Cuba sumaron 581 millones de euros. Véase Paul Hare, The Odd Couple: The EU and Cuba 1996-2008, Washington D.C., Brookings Institution, 2009. 
ropea y los 79 países que integran el Grupo África, Caribe y Pacífico. La candidatura cubana quedó postergada, al no existir un consenso entre los entonces quince miembros de la UE, pues tres países (no citados, aunque cabe suponer que la España de Aznar era uno de ellos) se mostraron reticentes a su ingreso al acuerdo y porque Cuba exigió que la ue no impusiera condiciones en materia de derechos humanos. Por otra parte, la ue había votado a favor de una moción de la Comisión de Derechos Humanos de la onu en Ginebra, en la que se condenaba la violación de derechos humanos en Cuba, por lo que Cuba retiró su solicitud de admisión a Cotonou en abril de 2000.

En 2001 se reiniciaron las conversaciones entre ambas partes y, pese a que la ue volvió a votar contra Cuba en Ginebra, no hubo ruptura y el gobierno cubano volvió a presentar su solicitud de ingreso a Cotonou.

En marzo de 2003 fue inaugurada la delegación de la Comisión Europea en La Habana, por el comisario para el Desarrollo y la Ayuda Humanitaria de la Comisión Europea, Poul Nielson. La uE recibió con beneplácito la solicitud de Cuba para formar parte del Acuerdo de Cotonou, lo que hacía suponer el inicio de una nueva etapa en las relaciones bilaterales. ${ }^{44}$

Sin embargo, a los pocos días de la partida de Nielson, una grave crisis afectó profundamente las relaciones exteriores de Cuba y en especial sus vínculos con Europa. En una acción concertada, agentes del Departamento de Seguridad del Estado cubano allanaron un centenar de viviendas, confiscaron máquinas de escribir, computadoras y equipos fotográficos y detuvieron a decenas de opositores, acusados de ser agentes al servicio de Estados Unidos; episodio represivo que pasó a conocerse como la Primavera Negra cubana.

La detención y condena de 75 disidentes a importantes penas en juicios sumarísimos en marzo de 2003 y el fusilamiento, días después, de tres cubanos por el secuestro de una embarcación tras un juicio breve y ejemplarizante, llevó a la condena unánime de la uE, al endurecimiento de las relaciones de ésta con

${ }^{44}$ Poul Nielson, European Commissioner for Development and Humanitarian Aid Official Opening of the Commission Delegation in the Gran Teatro of Havana, Cuba, 10 de marzo, 2003. 
el gobierno cubano y a un acercamiento con la disidencia. El Parlamento europeo declaró que las detenciones constituían "una violación inadmisible de los derechos humanos más elementales, especialmente en lo relativo a la libertad de expresión y de asociación política".

Además de la condena, la ue impuso una serie de sanciones contra Cuba, entre las que se incluían la cancelación de visitas de funcionarios cubanos de alto nivel a Europa, y la participación de diplomáticos europeos en actos culturales cubanos, pero excluyó las sanciones comerciales. ${ }^{45}$ La evidencia disponible sugiere que Fidel Castro nunca esperó una reacción semejante de la uE a la represión desatada por su régimen. Como respuesta, el gobierno de Cuba retiró nuevamente su solicitud de adhesión al Convenio de Cotonou, rechazó toda ayuda proveniente de la ue y acusó a los gobiernos europeos de colusión con Estados Unidos en la invasión de Irak. ${ }^{46}$

A partir de entonces el deterioro pareció imparable. Entre 2003 y 2005 Cuba y la Unión Europea se enfrascaron en una serie de conflictos diplomáticos que pasó a ser conocida por la prensa internacional como la "guerra de los cocteles". La disputa comenzó cuando las embajadas de diversos países miembros de la UE en La Habana tomaron la decisión conjunta de invitar a miembros prominentes de la disidencia cubana a recepciones diplomáticas en sus representaciones, en los días de fiesta nacional de cada uno de estos países. El gobierno cubano, que descalifica a la disidencia como "mercenarios al servicio de Estados Unidos", tomó la medida como una afrenta diplomática. ${ }^{47}$

En 2007 una nueva crisis diplomática estalló entre Cuba y Suecia, luego del discurso pronunciado por el ministro sueco de Asuntos Exteriores, Carl Bildt, ante el Consejo de Derechos Humanos de Naciones Unidas, en el que acusó a Cuba, junto a otras naciones de graves violaciones a los derechos humanos. La respuesta del representante cubano, Juan Antonio Fernández Palacios, fue ai-

45 "La ue congela su relación con Cuba por la represión de disidentes", en El País, Madrid, $1^{\circ}$ de mayo, 2003

${ }^{46}$ Declaración del MINREX, 17 de mayo, 2003.

${ }^{47}$ Véase, $B B C$ News, "Cuba's cocktail wars", 15 de julio, 2003 y "Truce declared in 'cocktail wars' between EU and Cuba", en The Independent, Londres, $1^{\circ}$ de febrero, 2005. 
rada, acusó a Bildt de actuar con "hipocresía", al criticar a Cuba y omitir cualquier referencia a la situación de la base estadounidense de Guantánamo, e incluso afirmó que el discurso del canciller recordaba a la Suecia "imperialista". "En Cuba no se persigue a los inmigrantes ni se intenta hacer una limpieza étnica para retener en el país a aquellos que respondan a los patrones raciales de los conquistadores vikingos".

El ministro sueco denunció además que su Embajada en Cuba tenía constancia de que las autoridades estaban interviniendo su correo diplomático, "una señal muy perturbadora [...] una ofensa muy grave a las reglas de comportamiento internacional". Poco después, la cancillería sueca protestó por el supuesto caso de violación de su valija diplomática y anunció que convocaría al embajador cubano en Estocolmo, Jorge D. Payret Zubiaur. ${ }^{48}$ Desde entonces Suecia ha sido uno de los países más reacios a cualquier revisión de la posición común europea.

La expansión de la ue hacia el este del continente en 2007 aumentó incluso más la presión sobre Cuba, en virtud de la determinación mostrada por varios países ex comunistas, como Polonia o la República Checa, por censurar al gobierno cubano, apoyar abiertamente a la disidencia cubana e intentar por diversos medios socavar las relaciones de la ue con la Isla. ${ }^{49}$

Con la llegada de José Luis Rodríguez Zapatero a la presidencia española, en abril de 2004, se vislumbró un posible cambio de rumbo de la política europea hacia Cuba. Bajo la égida del nuevo gobierno socialista, la diplomacia española intentó revertir la posición de presión de Aznar en la ue, con la propuesta de que comenzaran a suavizarse las sanciones. La ofensiva diplomática tuvo éxito relativo y Cuba restableció contacto con los países de la ue a comienzos de 2005, cuando el bloque suspendió la aplicación de sanciones políticas y después las eliminó definitivamente.

${ }^{48}$ El País, Madrid, 24 de marzo, 2007.

49 Larry Birns, "Prague Finds a Cause: Czech Republic aims to undermine EU-Cuban relations", en Spectrezine, noviembre de 2005. 
El relevo en el poder de Fidel por su hermano Raúl en 2006 abrió también otra vía a la labor del nuevo canciller español, Miguel Ángel Moratinos, quien llevó adelante los planes para el restablecimiento de los proyectos de cooperación, reuniones sobre los derechos humanos y los presos políticos. En octubre de 2009, en la segunda visita del ministro español a la Isla, se dieron por normalizadas las relaciones bilaterales.

En la creación de una política exterior hacia Cuba, la Unión Europea se ha enfrentado a la difícil tarea de coordinar las perspectivas contradictorias de sus estados miembros sobre este tema sensible y controversial. El logro de una estrategia común hacia Cuba que sea satisfactoria para todos sus estados miembros ha sido un objetivo importante de la política exterior de la UE, especialmente en vista de la unanimidad requerida para la mayoría de las decisiones tomadas dentro del marco de la Política Exterior y de Seguridad Común. Si se tienen en cuenta los vínculos históricos y económicos que unen algunos estados miembros a Cuba, es inevitable que los sentimientos encontrados en cuanto a la políica adoptada dificulten la coordinación de los 27. La presidencia rotativa de la Unión entre los 27 representa una dificultad añadida para la coordinación de la política exterior europea, pues cada país quiere dejar su impronta.

Al tratar de definir su propio enfoque hacia Cuba, la Unión Europea ha demostrado que el objetivo de evitar un conflicto con Estados Unidos sobre esta cuestión ha sido de alta prioridad, lo que ha contribuido a la renuencia de la UE para avanzar expedita y decisivamente hacia una política más activa con Cuba.

La ue y Cuba restauraron formalmente sus vínculos diplomáticos en octubre de 2008, y retomaron su diálogo político después de que la uE revocará las sanciones diplomáticas contra la Isla, a instancias de España. El comisionado europeo Louis Michel afirmó entonces que el acuerdo signado con el canciller cubano, Felipe Pérez Roque, era un "momento crucial para las relaciones entre Cuba y la uE." Pérez Roque elogió lo que llamó el respeto de Europa a la independencia política de su país. Cuba recibió dos millones de euros en ayuda humanitaria y de emergencia para la recuperación de los estragos provocados por el huracán, por 30 millones de euros. ${ }^{50}$

${ }^{50}$ BBC News, 23 de octubre, 2008.

(MÉxico 2012/1): 9-36

latino @mérica 54

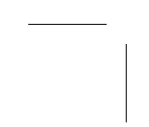


Tras una breve ceremonia la ue y Cuba acordaron reanudar su cooperación bilateral. Una declaración conjunta, suscrita por el canciller cubano y el comisario europeo llamó a respetar la independencia políica de Cuba así como la no intervención en sus asuntos internos. ${ }^{51}$

No obstante Cuba descartó normalizar relaciones con la uE si ésta no eliminaba la Posición Común. El nuevo canciller de Cuba, Bruno Rodríguez, afirmó en octubre de 2010 que la uE "sueña si considera que puede normalizar las relaciones con la isla caribeña sin eliminar la llamada Posición Común" en una intervención en la Asamblea General de la ond, que reiteró su condena al embargo estadounidense contra la Isla y en la que la ue volvió a votar en contra del bloqueo, tal y como lo ha hecho de modo invariable desde 1993.52

En una réplica a las críticas sobre la situación de los derechos humanos en Cuba, formuladas en el debate por un representante europeo, Rodríguez instó a la uE a ocuparse de sus políticas de emigración, la deportación de minorías, así como de la respuesta policial a las manifestaciones contra la crisis, entre otras cosas.

"No le reconocemos autoridad moral ni política alguna para criticar en materia de derechos humanos", afirmó el canciller cubano. "Con toda desvergüenza, y de manera infame, se dedica a premiar a agentes pagados por el gobierno de Estados Unidos en Cuba", subrayó el canciller cubano.

Ese mismo mes, los ministros de Exteriores de los 27, después de ratificar la Posición Común vigente desde 1996 respecto a Cuba, encargaron a la alta representante, Catherine Ashton, que estableciera contactos políticos con Cuba, con el fin de explorar posibles formas de avanzar en la relación bilateral, al tiempo que acordaron mantener por un año más la Posición Común, ${ }^{53}$ pese a los afanes de España por avanzar hacia un acuerdo bilateral entre las partes, que enfrentaron la firme oposición de países como Alemania, República Checa, Suecia, Hungría y Polonia. El acuerdo fue apoyado por un grupo de países que,

${ }^{51}$ Louis Michel cree que es el momento de normalizar relaciones con Cuba (AFP), 9 de marzo, 2008.

52 "Cuba descarta normalizar relaciones con la ue si no elimina la Posición Común", en El Mundo, Madrid, 27 de octubre, 2010.

53 Página 12, Buenos Aires, 25 de octubre, 2010. 
como Francia, lo consideran un reconocimiento a los cambios recientes en Cuba -como la liberación de 42 presos políticos y el anuncio de algunas reformas económicas-, frente a los socios más escépticos, que creían que esas medidas y gestos de La Habana no eran del todo suficientes.

Como resultado de tales gestiones, el ministro cubano de Relaciones Exteriores, Bruno Rodríguez Parrilla, sostuvo conversaciones oficiales en Bruselas en febrero de 2011 con Catherine Ashton, alta representante para los Asuntos Extranjeros y la Políica de Seguridad y vicepresidenta de la Comisión Europea, como continuidad del Diálogo Político de Alto Nivel establecido entre las partes. Durante la reunión, se expresó la disposición cubana de avanzar hacia el establecimiento de un marco bilateral de relaciones mutuamente aceptable.

Rodríguez Parrilla reiteró que la normalización de las relaciones entre las partes dependería de la eliminación por parte de la Unión Europea de los obstáculos existentes y de la comprobación en los hechos de su voluntad de avanzar en ese objetivo sobre bases recíprocas, con carácter incondicional y no discriminatorio, pleno respeto a la igualdad soberana de los estados, al marco jurídico y ordenamiento institucional de la partes, y total apego al principio de la no injerencia en los asuntos internos de los estados. ${ }^{54}$

En junio de 2011, Europa aplazó nuevamente sine die la revisión anual de las relaciones con La Habana. El Consejo de Ministros de Asuntos Exteriores de la Unión Europea, que tuvo lugar en Luxemburgo, no incluyó en su agenda la revisión anual de las relaciones con La Habana, pese a que este punto se aborda tradicionalmente cada mes de junio desde 1996, "porque la reflexión sobre un posible cambio 'está en curso' y no quiere elevar el debate a los ministros de Asuntos Exteriores mientras no exista 'un consenso', según destacó la prensa". ${ }^{5}$

Aun así, los ministros de Asuntos Exteriores de la Unión, ante la insistencia de España, para que explorara posibles vías de acercamiento a Cuba e iniciara

${ }^{54}$ En http://www.cubaminrex.cu/english/Actualidad/2011/febrero/Cuban\%20Foreign.html.

55 "Ashton aparca la revisión anual de las relaciones de los 27 con Cuba", en El Mundo, Madrid, 10 de junio, 2011. 
una serie de contactos con el gobierno cubano para alcanzar la normalización de las relaciones y un futuro acuerdo bilateral, pidieron un informe con el resultado de la evaluación para diciembre de ese mismo año.

La propia Ashton reconocía poco después que se estaba ante un "periodo de reflexión" en cuanto a las relaciones uE-Cuba, y que diciembre sería el momento de concreción respecto al mantenimiento o abandono de la Posición Común europea hacia Cuba. El anuncio europeo, por cierto, fue recibido con frialdad por las autoridades cubanas.

La "reflexión" se centraría, según los cancilleres, en la búsqueda de nuevas modalidades para avanzar en las relaciones con La Habana, recalcando, no obstante, que para concluir tal deliberación y plantear unas conclusiones es necesario alcanzar un "consenso" entre los 27, que por el momento no se da y que parece muy difícil de alcanzar.

Gran parte de las decisiones son intrincadas y especialmente en años recientes las reacciones a cualquier declaración son inmediatas. Un buen ejemplo de esto es la presidencia rotatoria de la uE, que si bien otorga voz en términos de equidad a los 27 países que conforman la Unión, complica enormemente la consecución de una acción exterior común, en la medida en que cada país prosigue su propia diplomacia y la uE tiene sus propias relaciones, pero al ser la presidencia giratoria, la asunción de la misma por un país distinto cada seis meses provoca parálisis y redundancias. Ello sin mencionar que cualquier modificación exige una unanimidad muy difícil de obtener entre naciones tan distintas. Proverbialmente, países como Suecia, la República Checa y el Reino Unido han sido los más reticentes a acercar posturas con La Habana, mientras que España es el principal defensor de la normalización de las relaciones.

Pese al impasse, los contactos "informales" de los diplomáticos cubanos con las cancillerías europeas han continuado, y existe la voluntad de incluir el tema de Cuba en la agenda de los ministros en su reunión anual del mes de julio, según fuentes comunitarias que insistieron, no obstante, que no hay una "obligación" para los 27 de revisar la Posición Común. Por su parte, fuentes eu- 
ropeas, apuntaron como "probable" que se dieran en el futuro contactos entre representantes cubanos y el Servicio de Acción Exterior de la UE. ${ }^{56}$

Mientras tanto, La Habana se encuentra a la expectativa de la decisión europea, si bien las declaraciones más recientes de sus funcionarios han sido frías y poco conducentes a un mejoramiento de las relaciones y a la reanudación del diálogo político entre las partes.

Así, por ejemplo, el director general para Europa del Ministerio cubano de Exteriores, Ernesto Sentí, aseguró que Cuba está "dispuesta a avanzar" hacia la normalización de las relaciones con la Unión Europea, si ésta plantea un marco "nuevo, diferente y bilateral", dejando en claro, no obstante, que debe ser a través de un diálogo entre iguales y que la posición común, que desde 1996 supedita tales relaciones a avances en democracia, "no enriquece" los contactos que, en su opinión, "ya existen" en el plano bilateral con distintos estados miembros, sin aclarar cuáles serían estos. Sentí explicó que, pese a la vigencia de la políica común, el régimen cubano mantiene "consultas políticas" con distintas capitales europeas. Inclusive, a decir de Sentí, la Posición Común tiene elementos que contravienen la carta de Naciones Unidas.

"Nosotros seguimos dando pasos importantes porque creemos en el Derecho Internacional, creemos en el respeto de los pueblos, pero ahora la bola está en territorio europeo para definir los próximos pasos a seguir", declaró Sentí en una entrevista en Bruselas, tras una reunión con los servicios de la alta representante de Política Exterior de la uE, Catherine Ashton.

Sentí afirmó que "Cuba es un país tan libre en todos los sentidos que nunca ha tenido presos políticos", al tiempo que rechazó que la Unión Europea pueda "pedir nada" a las autoridades de la Isla. También negó que las reformas económicas iniciadas por Raúl Castro, o la puesta en libertad de más de un centenar de disidentes en el último año hayan derivado de presiones internacionales, sino que las decisiones que toma Cuba "son acordes a su soberanía y a su línea de desarrollo". "Ningún Estado soberano que se respete tiene que admitir soli-

56 "Ashton aparca la revisión anual de las relaciones de los 27 con Cuba", en El Mundo, Madrid, 10 de junio, 2011.

(MÉxico 2012/1): 9-36

latino @mérica 54

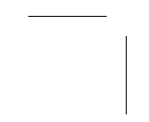


citudes de nadie. Cuba no actúa con el ánimo de tener que satisfacer a nadie, no lo hemos hecho con Estados Unidos en cincuenta años y Europa no tiene necesidad de ponerle condiciones a nadie."57

La crisis financiera en la que se halla sumida la ue no sólo ha exhibido los límites de la coordinación intereuropea, sino que ha relegado a un plano más que secundario las relaciones entre Europa y la Isla. Ante la patente desunión de los 27 en la coyuntura actual y la prevalencia de los intereses nacionales sobre una estrategia colectiva para enfrentar la inestabilidad financiera, la viabilidad de la política exterior europea está en entredicho. Por su parte, la renuencia cubana a siquiera discutir el tema de los derechos humanos en la Isla como parte de la agenda bilateral, al alegar sistemáticamente violación de su soberanía e injerencia en sus asuntos internos, supone un obstáculo aparentemente infranqueable para las buenas relaciones entre Cuba y el bloque europeo.

Resulta evidente que la relación entre la ue y Cuba se encuentra actualmente en un punto muerto y que las partes han llegado a un impasse en su diálogo político. En un nivel bilateral, las relaciones entre Cuba y varios países pertenecientes a la Unión son más fluidas y dinámicas que aquellas entre la Isla y el bloque, hecho que refuerza la noción de que la diplomacia europea es todavía una elevada expectativa, muy lejos de ser alcanzada. En la actual coyuntura, el relanzamiento de una asociación estratégica entre Cuba y la ue parece, por tanto, una posibilidad harto remota, especialmente ahora que Europa parece encontrarse absorta en su propio predicamento y que Cuba ha encontrado en China y Venezuela nuevos socios preferentes, que le han permitido, al menos temporalmente, salir de su aislamiento, sin llevar a cabo una autocrítica o revisión de sus políticas. ${ }^{58}$

Las flamantes y muy duras declaraciones de Fidel Castro, en las que el antiguo líder cubano lanza invectivas contra la Unión Europea y el nuevo gobierno

${ }^{57}$ Agencia EFE, Bruselas, 17 de junio, 2011.

${ }^{58}$ En un reciente discurso, ante una conferencia nacional de los comunistas cubanos, el primer secretario del pcc y presidente del Consejo de Estado de Cuba, Raúl Castro, aseguró que abrirse a un régimen pluripartidista "significaría legalizar las formaciones políticas del imperialismo", en referencia a los grupos opositores internos a los cuales, según su dicho, "EEUU brinda apoyo político y financiero". Véase, "Raúl Castro defiende el modelo de partido único", en Público, Madrid, 30 de enero, 2012. 
Mario OJeda Revah

de España, a propósito de la condena de parte de ambos, por la muerte del disidente Wilman Villar, ${ }^{59}$ a quien La Habana consideraba "recluso común", luego de 50 días de huelga de hambre, dan buena cuenta de esa reluctancia y hacen presagiar horas bajas para la relación entre la Isla y el bloque europeo:

El gobierno español y la destartalada Unión Europea, sumida en una profunda crisis económica, deben saber a qué atenerse. Produce lástima leer en agencias de noticias las declaraciones de ambas cuando utilizan sus descaradas mentiras para atacar a Cuba. Ocúpense primero de salvar el euro si pueden, resuelvan el desempleo crónico que en número creciente padecen los jóvenes, y respondan a los indignados sobre los cuales la policía arremete y golpea constantemente.

No ignoramos que ahora en España gobiernan los admiradores de Franco, quien envió a miembros de la División Azul junto a las SS y las SA nazis para matar soviéticos. [...] La derecha fascista de Aznar, Rajoy y otros servidores del imperio, debe conocer algo de las 16 mil bajas que tuvieron sus antecesores de la División Azul y las Cruces de Hierro con las que Hitler premió a los oficiales y soldados de esa división. Nada tiene de extraño lo que hace hoy la policía Gestapo con los hombres y mujeres que demandan el derecho al trabajo y al pan en el país con más desempleo de Europa. ${ }^{60}$

Recibido: 5 de septiembre, 2011.

Aceptado: 3 de febrero, 2012.

59 "La uE dice que la muerte del disidente plantea 'dudas' sobre el sistema judicial y penitenciario cubano", en Europa Press, 20 de enero, 2012

${ }^{60}$ Fidel Castro Ruz, "La fruta que no cayó", Reflexiones de Fidel, en Juventud Rebelde, Diario de la Juventud Cubana, La Habana, 25 de enero, 2012. 